\title{
EFEITOS DA SOMATOSTATINA NA PANCREATITE AGUDA NECROTIZANTE INDUZIDA PELA
} L-ARGININA EM RATOS

\author{
A.C.F. ARAUJO; V.R.C.D. FONSECA; A. HARTMANN; C.H. TOKARSKI; V.M. TRAUTWEIN
}

\author{
Hospital Universitário Evangélico de Curitiba e Faculdade Evangélica de Medicina do Paraná
}

A pancreatite aguda é condição resultante do processo inflamatório agudo no pâncreas podendo apresentar-se como distúrbio suave e autolimitado, ou sob a forma de doença grave de evolução muitas vezes fatal. Diversos estudos informam o emprego de somatostatina (SMT) ou seu análogo sintético, o octreotídeo, para tratamento da pancreatite, sem no entanto, haver consenso entre seus efeitos, doses a serem administradas ou oportunidade de uso. Objetivo: avaliar os efeitos de diferentes doses de SMT na evolução de pancreatite necrotizante induzida pela L-arginina em ratos. Material e Métodos: a amostra constitui-se de 31 ratos machos Wistar com pesos de 222,50 $18,52 \mathrm{~g}$. Aos ratos do grupo experimental $(\mathrm{n}=-21)$ inoculou-se por via intraperitoneal $500 \mathrm{mg} .100 \mathrm{~g}^{-1}$ de L-arginina (Merck art. 1.01542) fracionada em doses iguais e injetada em duas etapas com intervalos de 15 minutos. Esses animais foram subdivididos em 3 sub-grupos: animais não-tratados (grupo controle, $\mathrm{n}=10$ ), tratados com $100 \mathrm{mg} \cdot \mathrm{Kg}^{-1}$ de SMT (Humatropeâ-Lilly) via IP por 7 dias (grupo $1, \mathrm{n}=6$ ). Animais tratados com 200mg. $\mathrm{Kg}^{-1}$ de SMT via IP por 7 dias (Grupo 2, $\mathrm{n}=5$ ) e grupo de animais inoculados com solução salina isotônica por via intraperitoneal (grupo Normal, $n=10$ ). Ao sétimo dia de evolução, todos os animais foram sacrificados, sendo colhidos sangue para dosagens de amilase e glicemia sérica, pâncreas para avaliação histológica pela coloração de hematoxilina-eosina, tendo como critérios a porcentagem de ocorrência nos animais de edema, infiltração inflamatória, necrose parenquimatosa, hemorragia e classificaçãoi destes achados em ausente, leve, moderada e severa quando evidenciados. Resultados: no grupo normal não foram evidenciadas alterações histológicas pancreáticas e os níveis séricos de amilase estavam entre 320,10 $\pm 86,5 \mathrm{US} / 100 \mathrm{ml} \mathrm{e}$ glicemia $156 \pm 30,1 \mathrm{mg} / \mathrm{dl}$. No grupo controle observaram-se: infiltrado inflamatório moderado $(60 \%)$ e leve $(40 \%)$, edema moderado (70\%) e leve (30\%), necrose severa (10\%), moderada $(50 \%)$ e leve $(40 \%)$, ausência de hemorragia, a amilase sérica apresentou média de $1.878,1 \pm 526,89 \mathrm{US} / 100 \mathrm{ml}$ e glicemia média de $134,5 \pm 15,15 \mathrm{mg} / \mathrm{dl}$. No grupo 1 observou-se leve edema e leve infiltrado inflamatório capsular (100\%), as dosagens de amilase apresentaram média de $974,5 \pm 144,02 \mathrm{US} / 100 \mathrm{ml}$ e glicemia média de $142,33 \pm 54,70 \mathrm{mg} / \mathrm{dl}$. No grupo 2 observou-se apenas edema em $100 \%$ dos animais com amilase média de 953,40 $225,16 \mathrm{US} / 100 \mathrm{ml}$, glicemia média de $175 \pm 42,9 \mathrm{mg} / \mathrm{dl}$. A avaliação estatística não revelou diferenças significativas entre os valores de glicemia em todos os grupos $(\mathrm{p}=0,326)$, contudo, os grupos 1 e 2 apresentaram diferenças nas dosagens de amilase $(\mathrm{p}=0,00265)$ em relação ao grupo controle. Conclusão: a SMT administrada por via intraperitoneal, nas doses de $100 \mathrm{mg} \cdot \mathrm{Kg}^{-1}$ e $200 \mathrm{mg} . \mathrm{Kg}^{-1}$ durante sete dias, melhorou a reação inflamatória, impediu os efeitos necrotizantes bem como baixos os níveis séricos de amilase, independente da dose utilizada no modelo experimental de pancreatite aguda necrotizante induzida pela L-Arginina em ratos. 